\title{
Storms and extreme events: Insights from the historical and paleo record
}

\author{
Simon E. Engelhart', J.E. Pilarczyk ${ }^{2}$ and A. Rovere ${ }^{3}$
}

\begin{abstract}
Past land-falling coastal storms have left geological imprints. Studying them can help gauge the intensity/frequency of extreme storm events beyond the instrumental and historical record and provide insights on the severity of storms under warmer climates.
\end{abstract}

The potential for increased impacts from coastal storms is among the most concerning aspects related to future climate warming. Increasing impacts from these events can be broadly related to two factors. Firstly, it is expected that as relative sea level (RSL) continues to rise through 2300 , significant regions, including major metropolitan areas, will be exposed to inundation without requiring any increase in the strength of storms (e.g. Garner et al. 2017). Secondly, increased intensity and frequency of the most extreme events is possible. Together, these two causative factors indicate that coastal flooding is likely to double by 2050 due to the combined effect of RSL rise and storm surge (Vitousek et al. 2017). The study of landfalling coastal storms under future climate scenarios accelerated in the aftermath of Hurricane Sandy (2012) and has been under the spotlight again after Typhoon Haiyan (2013), Hurricanes Harvey, Irma and Maria (2017), and Hurricanes Florence and Michael and Typhoon Mangkhut (2018).

Our understanding of how storms are related to climate is limited by the short instrumental and historical record. A solution to this is to develop and apply proxies for past storms that can improve our ability to provide insights into future storms under a warmer climate (e.g. linkage between proxy sea surface temperature records and hurricane frequency/intensity). Here we describe the characterization of storms in the paleo record including those from historical, Holocene, Late Pleistocene, and Last Interglacial periods, and identify some of the main questions that still need to be answered.

\section{Historical storms}

Recent land-falling storms provide opportunities to characterize the sedimentary and geomorphic signatures of events of known intensity and impact. The deposits left behind by instrumentally recorded events (e.g. Hurricane Irma, Fig. 1a) serve as important modern analogues for interpreting older historical and paleo events for which available information is limited (Brandon et al. 2014). Lessons learned in the wake of Typhoon Haiyan's unusual bore-like (deep, high-velocity flow and short inundation duration in contrast to the more commonly reported gradual rise and prolonged inundation) storm surge provide important insight into the limitations of distinguishing storm impacts from those associated with tsunamis (Soria et al. 2017), whereas insight gained from studies of sediments deposited by Hurricanes Camille and Katrina showed that similarly intense storms have impacted coastlines of the Gulf of Mexico multiple times over centennial timescales (Bregy et al. 2018).
Emerging research uses modern and historical storm analogues to validate techniques that can be used to enhance the reconstruction of long-term records that capture the variability in recurrence and intensity of storms over centennial to millennial timescales. Sediment grain size is used to infer the flow depth of water over the coastal barrier during past storms (Woodruff et al. 2008), and foraminifera are being used to determine sediment provenance and distance of transport by storm surges (Kosciuch et al. 2018). In the absence of real-time tide-gauge data, these techniques are the only means to reconstruct the flow depth and inland extent of the storm surges that predate the instrumental record, providing information concerning variability in storm intensity under different climates than today's.

\begin{abstract}
Late Pleistocene and Holocene storms
Traditionally, the reconstruction of land-falling storms beyond the historical record has focused on the identification of anomalous high-energy sediments within low-energy sedimentary environments such as coastal lakes, sinkholes, and fresh/salt marshes (Fig. 1) or erosive features within salt marshes.

These methods have successfully produced centennial- to millennial-scale records of storm impact on coastlines, although there are complications such as barrier height changes over time; the changing sensitivity
\end{abstract}

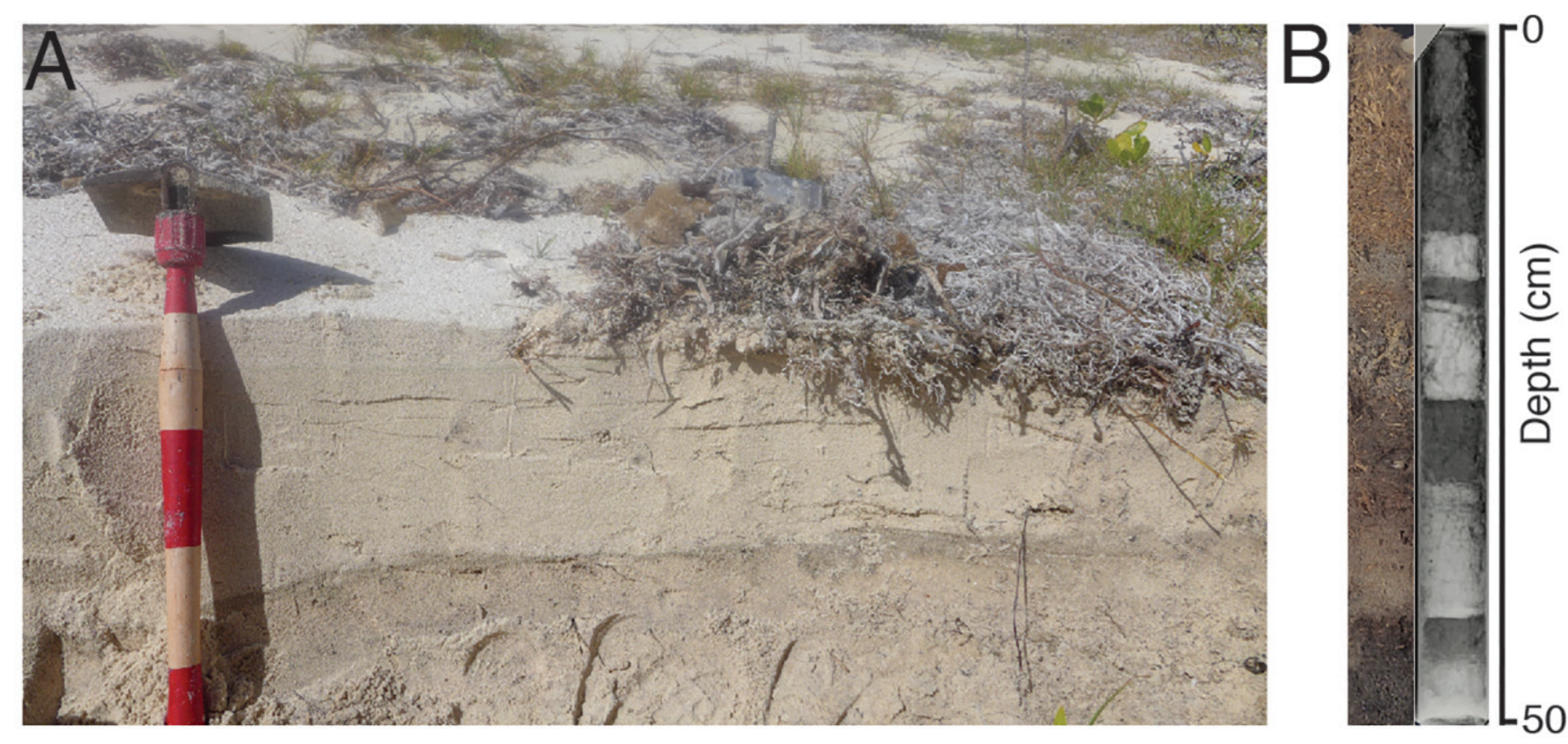

Figure 1: (A) Hurricane Irma (2017) sediments deposited on top of beach sand on the island of Anegada, British Virgin Islands. The deposit represents an important modern analogue for interpreting a series of paleo-storm and tsunami deposits preserved within coastal ponds on the island. (B) Overwash deposits (sands and silts) from historical storms (photograph and X-ray view) recorded within saltmarsh peat at Succotash Marsh, Rhode Island, USA. Cores were taken in close proximity to those in Donnelly et al. (2001). 


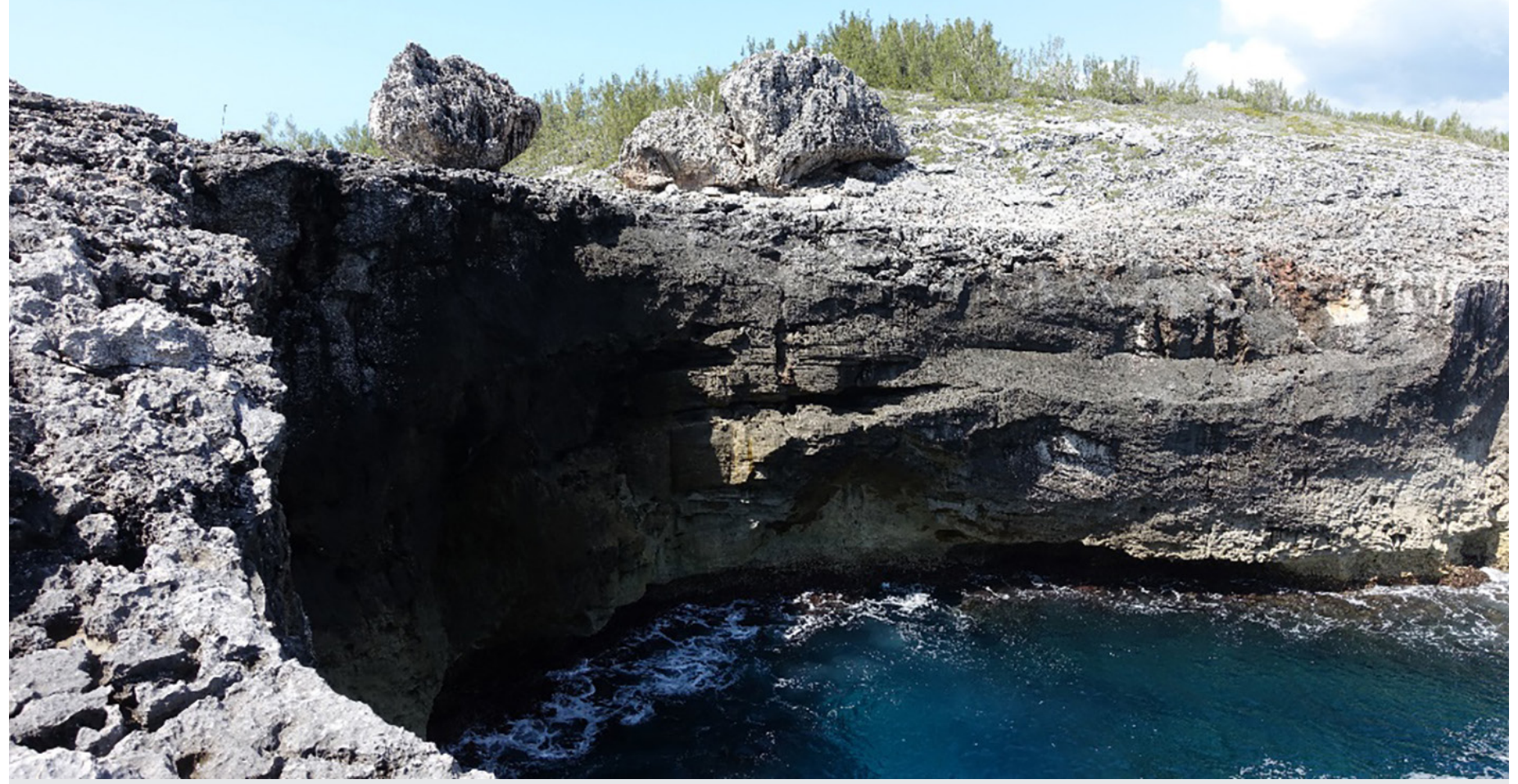

Figure 2: "Cow and Bull," two large boulders deposited during the LIG on a steep cliff in the island of Eleuthera, The Bahamas. Researchers are debating whether these boulders were deposited by LIG "superstorms" (Hearty 1997), storms similar to modern ones (Rovere et al. 2017), or tsunamis (see discussion in Engel et al. 2015). Others interpret these landforms as karst remnants (Mylroie 2018).

of coastal sites to inundation as RSL and coastline position changes through time; and the preservation potential of the storm deposited sediments. Some of these concerns can be addressed by more recent work using deep-sea sediment cores that contain storm-triggered turbidites as a potential record (e.g. Toomey et al. 2017). Submerged records, including those from blue holes and the deep sea, have the additional advantage of comprising comparatively long records that can stretch into the late Pleistocene (e.g. Toomey et al. 2017) compared to many of the marsh-and coastal lagoon-based approaches that are typically limited to the late Holocene (last 4000 years; e.g. Donnelly et al. 2001). The impacts of storms have also been studied in high-energy environments using boulder deposits (e.g. Cox et al. 2018), but the reconstruction of long-term records is complicated by difficulties in dating deposits and separating individual events from large-scale boulder fields.

\section{Deeper in the past}

Boulder and wave runup deposits are the primary parameters used to reconstruct extreme storms on longer timescales (e.g. during past interglacials) that can be used as process analogues for the warmer world predicted for 2100 and beyond. One such candidate for the study of paleo extreme storms is the Last Interglacial, (LIG, ca. 125 kyr BP). Hansen et al. (2016) used numerical simulations and paleo storm proxy data to propose that a future warmer climate could be characterized by "superstorms" (intensities not measured in historical times). They posit that similar "superstorms" may have happened in the western Atlantic during the LIG thanks to geological evidence reported from The Bahamas (Hearty 1997).
This evidence consists of very large boulders deposited during the LIG on the island of Eleuthera (Fig. 2) and LIG chevron ridges/ runup deposits reported in The Bahamas and Bermuda. The interpretation of these landforms as being indicative of stronger storms during the LIG remains controversial (Engel et al. 2015). Nevertheless, Hansen et al. (2016) revived the study of geological storm proxies in past warmer climates, which had been neglected since the late 90 s. Since the publication of Hansen et al. (2016), several papers (including comments and replies arguing about the interpretation of the geological proxies) were published on LIG "superstorms" (Mylroie 2018 and comments and replies therein). The main conclusion that can be drawn from these papers is that more research is needed on extreme storms at these timescales. New-generation hydrodynamic models can help unravel the energy of different coastal storms and hence their ability to generate particular landforms (see Rovere et al. 2017 for an example on LIG boulders).

\section{Future research directions}

Although still underutilized on a global scale, long-term geologic reconstructions of past storms are necessary to capture important information concerning the variability in storm frequency and magnitude - information requested by coastal managers as well as insurance companies. Future research directions include expanding the proxy toolkit to extract crucial information from deposits left by land-falling storms such as highimpact events that have a smaller surge but intense rainfall. Further, there is a need to expand Late Pleistocene and Holocene records beyond the Atlantic and Gulf coasts of North America, identify other LIG storm proxies beyond the frequently cited Western Atlantic boulder records, and reduce the subjectivity in the geological interpretation of the intensity of LIG extreme storms. Information derived from geological evidence can be used to constrain and validate inundation models, enhancing our ability to assess the hazard and associated risk for many of the world's coastlines.

\section{AFFILIATIONS}

'Department of Geosciences, University of Rhode Island, Kingston, USA

2Department of Earth Sciences, Centre for Natural

Hazards Research, Simon Fraser University, Burnaby, Canada

${ }^{3}$ Leibniz Center for Tropical Marine Research,

University of Bremen, Germany

\section{CONTACT}

Simon E. Engelhart: engelhart@uri.edu

\section{REFERENCES}

Brandon CM et al. (2014) Sci Rep 4: 7366

Bregy JC et al. (2018) Mar Geol 396: 26-42

Cox R et al. (2018) Ear-Sci Rev 177: 623-636

Donnelly JP et al. (2001) GSA Bull 113: 714-727

Engel M et al. (2015) Atmos Chem Phys Discuss 15: C6270-C6281

Garner AJ et al. (2017) Proc Natl Acad Sci 114: 201703568

Hansen J et al. (2016) Atmos Chem Phys 16: 3761-3812

Hearty PJ (1997) Quat Res 48: 326-338

Kosciuch TJ et al. (2018) Mar Geol 396: 171-185

Mylroie JE (2018) J Coast Res 34: 1471-1483

Rovere A et al. (2017) Proc Natl Acad Sci 114: 201712433

Soria JLA et al. (2017) Sed Geol 358: 121-138

Toomey MR et al. (2017) Geol 45: 1047-1050

Vitousek S et al. (2017) Sci Rep 7: 1399

Woodruff JD et al. (2008) Geol 36: 391-394 